\title{
CHRISTENSEN, Carl C., Princes and Propaganda. Electoral Saxon Art of the Reformation
}

\section{Olivier Christin}

\section{OpenEdition}

Journals

Édition électronique

URL : http://journals.openedition.org/ifha/2029

DOl : $10.4000 /$ ifha. 2029

ISSN : 2198-8943

\section{Éditeur}

IFRA - Institut franco-allemand (sciences historiques et sociales)

\section{Référence électronique}

Olivier Christin, «CHRISTENSEN, Carl C., Princes and Propaganda. Electoral Saxon Art of the Reformation », Revue de l'IFHA [En ligne], Date de recension, mis en ligne le 01 janvier 1994, consulté le 22 septembre 2020. URL : http://journals.openedition.org/ifha/2029; DOI : https://doi.org/10.4000/ifha. 2029

Ce document a été généré automatiquement le 22 septembre 2020.

(C)IFHA 


\title{
CHRISTENSEN, Carl C., Princes and Propaganda. Electoral Saxon Art of the Reformation
}

\author{
Olivier Christin
}

1 Ce petit livre de C.C.C., dont on connaît notamment le travail sur la Réforme et l'art (Art and Reformation in Germany, Athens, 1979), analyse quelques-unes des images les plus célèbres et les plus répandues de la première moitié du XVIe siècle allemand. Il est, en effet, consacré aux images (gravures surtout, mais aussi retables et médailles) d'origine saxonne qui représentent les Électeurs de la branche Ernestine et qui, en même temps, se rattachent explicitement à la Réforme. C'est donc la combinaison de l'iconographie politico-religieuse et du portrait princier qui retient l'attention de l'auteur et le conduit à poser le problème de la propagande par l'image.

2 Selon un plan chronologique très clair, l'auteur aborde successivement les représentations de Frédéric le Sage avant la Réforme (qui mettent en évidence sa dévotion mariale, son attachement à saint Barthélemy ou à sainte Anne), les débuts de l'iconographie protestante, les grands portraits collectifs et commémoratifs des années 1530 (comme les triptyques de 1535 environ, aujourd'hui à Nuremberg et Hambourg, représentant les trois électeurs saxons), les illustrations de livres (notamment la célèbre page de titre représentant Luther et Jean le Constant agenouillés de part et d'autre du Christ en croix), les représentations de la ligue de Smalkalde et de l'Intérim, et enfin les derniers portraits de Jean Frédéric en héros-martyr de l'Évangile, le visage barré par la blessure reçue à Mühlberg (1547).

3 L'approche de C.C.C. se caractérise par son souci de concilier analyse iconographique minutieuse et étude du contexte politique et religieux (commanditaire de l'image, diffusion, circonstances de la fabrication). L'auteur éclaire ainsi de façon très convaincante quelques questions importantes, comme l'apparition du motto VDMIAE (Verbum Domini Manet in Aeternum) étroitement lié à l'engagement religieux des Électeurs, le rôle des pages de titre illustrées ou encore la signification des nombreuses représentations des Électeurs (ou de l'un d'entre eux seulement) assistant au Baptême 
du Christ (l'auteur y voit une condamnation à la fois des catholiques et des anabaptistes). Ce livre, d'une lecture agréable, ouvre ainsi de très intéressants aperçus sur l'histoire politique et culturelle de la Réforme.

4 Olivier CHRISTIN 